\title{
Distance Training of Higher Education Specialists Using Virtual Presence Technologies
}

\author{
Valerii Semenets \\ ORCID 0000-0001-8969-2143 \\ Department of Metrology and \\ Technical Expertise \\ Kharkiv National University of \\ Radio Electronics \\ Kharkiv, Ukraine \\ valery.semenets@nure.ua \\ Evgen Chuguy \\ ORCID 0000-0001-5028-7968 \\ Department of Biomedical Engineering \\ Kharkiv National University of \\ Radio Electronics \\ Kharkiv, Ukraine \\ evgen.chuhuy@nure.ua
}

\author{
Oleg Avrunin \\ 0000-0002-6312-687X \\ Department of Biomedical Engineering \\ Kharkiv National University of \\ Radio Electronics \\ Kharkiv, Ukraine \\ oleh.avrunin@nure.ua \\ Yana Nosova \\ ORCID 0000-0003-4310-5833 \\ Department of Biomedical Engineering \\ Kharkiv National University of \\ Radio Electronics \\ Kharkiv, Ukraine \\ yana.nosova@nure.ua
}

\author{
Tatyana Nosova \\ ORCID 0000-0003-4442-8001 \\ Department of Biomedical Engineering \\ Kharkiv National University of \\ Radio Electronics \\ Kharkiv, Ukraine \\ tatyana.nosova@nure.ua \\ Oleksandr Gryshkov \\ ORCID 0000-0002-3116-8792 \\ Institute for Multiphase Processes \\ Leibniz University of Hannover \\ Hannover, Germany \\ gryshkov@imp.uni-hannover.de
}

\begin{abstract}
The technologies of creating modern educational content based on video with the effect of presence are considered. The features of the technology for creating a modern panoramic video and examples useful for creating educational content in different fields are given.
\end{abstract}

Keywords-high resolution, educational process, panoramic video, viewing angle, situational problems

\section{INTRODUCTION}

Modern requirements for the development of disciplines and the results of the final training of modern university graduates are based on the formation of competencies integrated characteristics aimed at developing the ability to combine the acquired knowledge, abilities and skills into a single whole to achieve the goal, taking into account the context, specific situation and functionality. At the same time, the drawbacks of traditional training at present are the formality of the knowledge gained and the insufficient ability to apply their practical activity, which generally indicates the incomplete formation of professional thinking, which is absolutely necessary with a modern approach to employment [1-2].

Modern challenges associated, for example, with the pandemic of the COVID-2019 virus, and the necessary strict measures of long-term total quarantine in an emergency situation, lead to a complete reorientation to distance learning methods, which from the auxiliary become the main ones throughout the teaching cycle of most disciplines. Therefore, along with the possibilities of placing electronic educational materials with presentations, calculations and tests, as well as organizing interactive interaction with students in video conferencing modes, it is necessary to provide the educational process with the most realistic content available for distance learning services. Video content based on panoramic video technologies can become such content at the present stage.
The widespread use of panoramic video technology appeared only a few years ago. Panoramic refers to video with viewing angles in the horizontal $360^{\circ}$ and vertical $180^{\circ}$ planes, respectively. Thanks to these viewing angles, such a video is also called spherical. Moreover, in most viewing programs, the user can change the viewing angle interactively using manipulators or touch screen systems. Modern panoramic cameras, as a rule, have two wide-angle (over $180^{\circ}$ ) lenses overlapping each other. There are models with a large number of standard lenses, for example: 6 (Insta 360 evo) (Fig.1), 8 (VUZE 360) and even 24 (Surround $\times$ 24). The advantage of multi-lens models is a smaller number of geometric distortions compared to the image formed by wide-angle lenses, however, there is a greater likelihood of artifacts from combining images formed by different cameras and differences in illumination may occur [3-5].

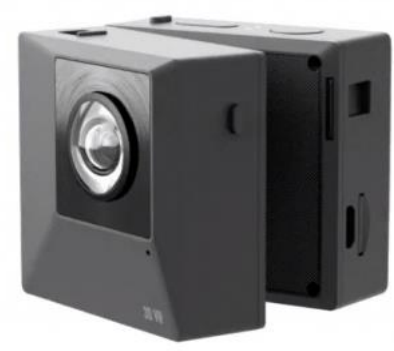

Fig. 1. Panoramic camera Insta 360 evo.

In fact, to obtain panoramic video, the device registers video streams from different cameras, and then combines them - the so-called "stitching" (Fig.2).

Compared to traditional ones, panoramic videos take up a large amount, which is associated not only with an increase in visibility, but also due to, as a rule, high resolution, for example, $4 \mathrm{~K}(3840 \times 1920), 5.7 \mathrm{~K}(5760 \times 2880)$ and $8 \mathrm{~K}($ $7680 \times 4320)$ at a frequency of not less than 30 frames per second. For example, when working with an Insta360 EVO 
device that has 2 recording cameras with wide-angle lenses (with a viewing angle of $200^{\circ}$ ), $2 *$.insv files from each camera are formed, which are then programmatically converted to a panoramic video file in * .mp4 format. So, a 9 -second panoramic video with a resolution of $5 \mathrm{~K}$ in *.mp4 format occupies $149 \mathrm{MB}$ with the size of two * insv files of $65 \mathrm{MB}$ each; A 27-second panoramic video in the resolution of $1600 * 800$ in the *.mp4 format occupies $420 \mathrm{MB}$ with the size of two * insv files of $169 \mathrm{MB}$ each; A 7-second panoramic video in low resolution $800 * 400$ in *.mp4 format occupies $40 \mathrm{MB}$ with the size of two * insv files of $60 \mathrm{MB}$ each. You can view this content right away from your smartphone with the help of a specialized Holo Frame screen cover, 3D glasses, as well as standard virtual reality glasses (Oculus Go, Samsung Gear VR, etc.).

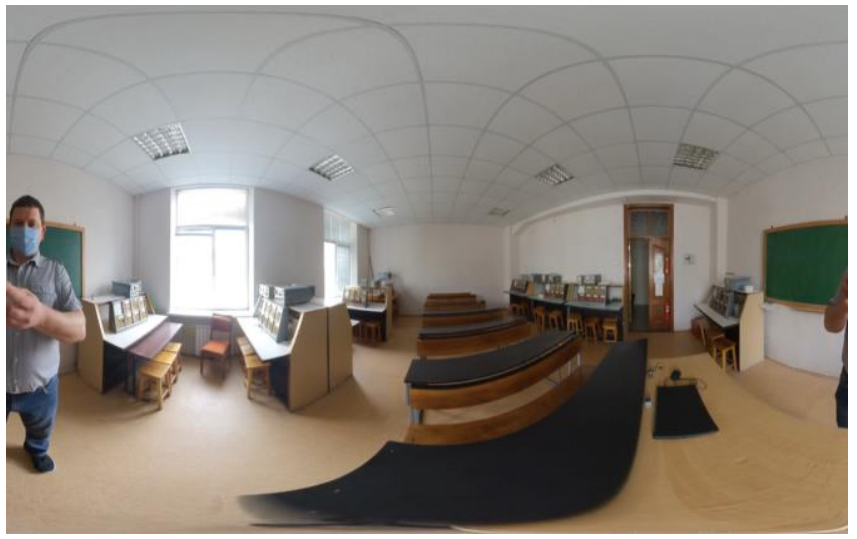

Fig. 2. Frame reversal training video 360 .

It should be recognized that lowering the resolution below Full HD $(1920 \times 1080)$, or close to it, significantly degrades the image quality and does not allow to fully realize the effects of scaling. Given the prospects for technology development, at the present stage it is advisable to use the resulting video with a resolution close to $4 \mathrm{~K}(3840 \times 1920)$.

Panoramic view, interactive control and high resolution allow you to realize the key advantage of such a panoramic video - the effect of presence. Given that expensive equipment is often used in medicine, access to which is limited for development [6-7], as well as various new approaches and methods, for example, in surgical treatment [8], which must be demonstrated in order to acquire practical skills [9], it is advisable to use panoramic educational video content for these purposes.

Also, it is advisable for conducting laboratory workshops in technical disciplines [6-7], where students need to get the most out of the real work of not only one device, but, in some cases, a whole complex of complex equipment [10-12].

Even when listening to a standard lecture, or shooting a video of a practice lesson, an interactive panoramic video allows you to create the effect of being in the audience, which is very important for a long distance learning form, when for a long time the possibility of real communication and being in the audience is lost.

\section{USING A VIDEO WITH A PRESENCE EFFECT}

For several decades, information technology has been actively used in training. At the same time, a huge number of approaches for distance learning have been proposed, ranging from digitized training materials, video lectures, and test programs $[13,14]$, to the organization of video conferencing, interactive courses and modeling of typical situations using virtual reality tools [15-16]. In medicine, such technologies make it possible to solve situational problems with virtual patients and simulate surgical operations with maximum realism, while training engineers to remotely perform laboratory work not only using virtual equipment, but also on real equipment using interactive systems with feedback.

Despite the fact that a sufficient number of distance learning courses have been developed and applied throughout the world in various fields of knowledge, until now, in the classical university educational process, these technologies have been only a kind of high-tech support for traditional teaching methods and have been used mainly only to further consolidate practical skills, or with independent work of students.

\section{SituATIONAL TASKS}

A special role in the educational process when acquiring practical skills is brought by the solution of situational problems, which allow creating conditions as close as possible to real tasks and circumstances. Such a concept for learning is realized by describing a real situation that needs to be resolved by answering, in the simplest case, a list of issues of a problematic nature, or by completing a series of tasks that characterize the effectiveness of the knowledge used and the chosen approach.

This may be the determination of a malfunction of a device or system in engineering, the diagnosis and determination of adequate therapy for a patient in medicine, the solution of real-life problems in other areas. In the process of solving situational problems, such universal methods of working with information are formed as analysis, classification, recognition, structuring, generalization, comparison, search for analogies, choice of options, and synthesis of new knowledge. This approach has a clear practical orientation and allows you to implement the skills acquired in the learning process and the above to work in a real situation.

The simplest and most traditional way of presenting situational tasks is their textual description. Given the features of the perception of information, especially among modern students who are accustomed to rely more on visual images in the world of digital gadgets, this approach, unfortunately, does not fully ensure immersion in the real task.

In addition, in many areas it is precisely a comprehensive assessment of information from various sources. To increase the effectiveness of such an approach, increase the reliability and make the created situation more realistic, it is advisable to develop content that allows maximum approximation to the real environment. To do this, it is necessary to use approaches with a high level of interactivity, created on the basis of virtual reality technologies [1], panoramic video [2], which make it possible for a modern student to interest and transfer the solution of a situational problem from a routine training task to the most realistic environment with which you can interact and get additional information that minimally limits the creative activity of the student. 
Only immersion in the environment with the help of carefully thought-out interactive video content with the effect of presence allows you to fully use the mechanisms of mental activity to make decisions and develop practical skills in solving situational problems. This allows you to take a illustration of the event to a new level; actualization of the problem and requires a whole range of measures and the development of appropriate methodological material to create a realistic virtual environment that adequately simulates typical situations. It is advisable to apply approaches to creating virtual patients in medicine, a virtual laboratory base $[3,4]$ with the technical focus of training.

The main goal of situational tasks is to develop the competencies and skills necessary to solve practical problems. And in the first place is the creation of quality content that simulates the environment in the context of which the task arises. All aspects of integrative approaches to learning are clearly manifested here, which allows us to develop and produce new ones based on the previously acquired comprehensive knowledge and skills.

\section{CONCLUTION}

The widespread introduction of situational tasks allows us to transfer the educational process at universities in advanced courses to a qualitatively new level, which allows us to acquire practical knowledge and to model the ability to make responsible decisions. This, in turn, increases the interest and self-esteem of students, and develops their willingness to act in real situations, which is taken into account in employment.

When using panoramic content, the student, while at home, has the opportunity to see what is in the classroom in the appropriate directions, either by standard means of personal computers, or by mobile phone or tablet (moving his gadget to the side). Thus, the student has the opportunity to observe the teacher at the same time, which, for example, explains the laboratory work at the study layout, the presentation of control commands and data processing on the monitor screen, supporting materials, such as displayed on the board, additional equipment and by the reaction of classmates next to him in the audience.

Despite the fact that it takes a lot of time to create really high-quality educational panoramic content, it allows to increase the efficiency of the educational process, especially in quarantine, and promotes social adaptation of people with special educational needs in the implementation of inclusive education. Panoramic video technologies allow you to take training videos to a whole new level, providing an almost full-fledged presence effect for the student, allowing you to interactively change the angle of view and observe the manipulations in all directions of the space available for viewing. The prospect of work is the creation of virtual laboratories and panoramic video-content of complete research based on the laboratories of NIFE and IMP which situated in the Leibniz University of Hannover.

\section{ACKNOWLEDGMENT}

The exchange program with East European Countries funded by DAAD (Ostpartnerschaften, project number 54364768) and joint Ukraine-Germany project MESUBMBF 2019-2020 "3D-Model - Implementation of rapid prototyping to design and model the upper respiratory tract in normal and typical pathologies"

\section{REFERENCES}

[1] V. Kobzev, V. Semenets and V. Filatov, "Components of the information system for monitoring the quality of education in Kharkov National University of Radio Electronics", in 7th Int. scientific and technical conf. Information systems and technologies (IST-2018), Kharkiv-Koblevo, 2018, pp. 51-54.

[2] V. Semenets, I. Svyd and L. Saikivska, "Methods of improving the quality of preparation of technical specialists", in Engineering education: challendes and developments : materials of the IX International Scientific and Methodological Conference, Minsk, Belarus, 2018, pp. 415-416.

[3] Iorns, Thomas, and Taehyun Rhee. "Real-time image based lighting for 360-degree panoramic video." Image and Video Technology. Springer, Cham, 2015.

[4] Youvalari, Ramin Ghaznavi, et al. "Efficient coding of 360-degree pseudo-cylindrical panoramic video for virtual reality applications." 2016 IEEE International Symposium on Multimedia (ISM). IEEE, 2016.

[5] Kwon, Oh-Seol, and Yeong-Ho Ha. "Panoramic video using scaleinvariant feature transform with embedded color-invariant values." IEEE transactions on Consumer Electronics 56.2 (2010): 792-798.

[6] O. Avrunin, O. Kruk, T. Nosova and V. Semenets, "Technical aspects of the development of virtual laboratory works on technical educational disciplines", Open Education, vol. 3, pp. 11-17, 2008.

[7] O. Avrunin, S. Sakalo and V. Semenetc, "Development of up-to-date laboratory base for microprocessor systems investigation," 2009 19th International Crimean Conference Microwave \& Telecommunication Technology, Sevastopol, 2009, pp. 301-302.

[8] Gubanov, A. V., Zhemchuzhkina, T. V., Nosova, T. V., \& Nosova, Y. V. (2014). Electromyographic data processing module 5th International radio electronic forum «Applied electronics. Status and Development Trends», Conference «Problems of Biomed Engineering. Science and Technology, 3, 25-27.

[9] Nosova, Ya V., Kh I. Faruk, and O. G. Avrunin. "A tool for researching respiratory and olfaction disorders." Telecommunications and Radio Engineering 77.15 (2018): 1389-1395.

[10] Avrunin, O. "Development of Automated System for Video Intermatoscopy/OG Avrunin, V. Klymenko, A. Trubitcin, O. Isaeva." Proceedings of the IX International Scientific and Practical Conference International Trends in Science and Technology. Vol. 2. 2019.

[11] Avrunin, O., Ya Nosova, and S. Khuadaieva. "Features of creation technologies for educational panoramic video content." Modern approaches to the introduction of science into practice. Abstracts of X International Scientific and Practical Conference. San Francisco, USA 2020. Pp.256-259.

[12] Nosova, Y., I. Younouss Abdelhamid, and O. Gryshkov. "Using 3D printing technology to full-scale simulation of the upper respiratory tract." Informatyka, Automatyka, Pomiary W Gospodarce I Ochronie Środowiska, Vol. 9, no. 4, Dec. 2019, pp. 60-63, doi:10.35784 / iapgos.681.

[13] Saghir, Ali. "Influence of Vidio Games in Learning." Journal of Emerging Trends in Computing and Information Sciences 7.8 (2016): 338-342.

[14] I. Tarasov. Organization of the educational process in the design of digital devices using an initial level based boards FPGA Spartan-6 company Xilinx. Components and Technologies, 2011,12, pp.10-14.

[15] V. Semenets, V. Kauk, O. Avrunin. "The advanced technology of remote training at the initial process" ["Vprovadjennya tehnologiy dystantsiynogo navchannya u navchalnii protses"], High School, 2009. - No. 5 .- P. 40- 45.

[16] Avrunin, Oleg G., T. Nosova, and V. Semenets. "Experience of Developing a Laboratory Base for the Study of Modern Microprocessor Systems." Proceedings of I International Scientific and Practical Conference "Theoretical and Applied Aspects of Device Development on Microcontrollers and FPGAs" MC\&FPGA-2019, Kharkiv, Ukraine, 2019. P. 6-8. 